\title{
Research on the Teaching Mode of Advanced Mathematics under the Background of Course Ideology and Politics
}

\author{
Jun Xie ${ }^{1, *}$, Yue Yang ${ }^{1}$, Weili Liu ${ }^{1}$ and Xiao Lin ${ }^{1}$ \\ ${ }^{1}$ Teaching and Research Office of Mathematics, Department of Basics, PLA Dalian Naval Academy, Dalian 116018, \\ Liaoning, PR China \\ *Corresponding author. Email: xiao_xiejun@126.com
}

\begin{abstract}
It is one of the goals of higher mathematics teaching to cultivate students' realistic spirit, refinement spirit, and the quality of overcoming difficulties by incorporating ideological and political elements in the advanced mathematics classroom. This article explores the methods and means of implementing ideological and political in higher mathematics courses, and deeply explores the ideological and political elements contained in higher mathematics, so as to realize the unity of ideological and political education and professional knowledge, so as to achieve the purpose of better training students' ability.
\end{abstract}

Keywords: Advanced Mathematics; Classroom Teaching; Teaching Method; Teaching Mode; Ideological and

Political

\section{INTRODUCTION}

In September 2018, President Xi Jinping pointed out at the National University Ideological and Political Work Conference, "We must adhere to the central link of morality and cultivating people, and put ideological and political work throughout the whole process of education and teaching, so as to realize the whole process of educating people and all-round education. As the main channel of classroom teaching, the ideological and political theory courses must be strengthened while improving, and other courses must be well maintained and cultivated fields of responsibility, so that various courses and ideological and political theory courses should go in the same direction and form a synergistic effect"[1]. As an important public basic course, advanced mathematics is the foundation of many engineering majors, and it plays an important role in the study of students' follow-up professional courses and the cultivation of thinking. The introduction of ideological and political elements plays an important role in the teaching reform of higher mathematics. The reform of curriculum ideological and political teaching makes advanced mathematics classroom more life-oriented and intuitive not only for in-depth interaction with students, but also for guiding students to establish a correct outlook on life. There exist methods of integrating curriculum ideology and politics into advanced mathematics [2].

\section{ATTACH IMPORTANCE TO COMMUNICATION AND INTERACTION WITH STUDENTS IN THE FIRST CLASS}

As a teacher, you should realize that the first lesson will have a profound impact on students' subsequent learning of the entire course. So it is very important to do a good job of ideological and political education in the first class, incorporating ideological and political elements in the first class will help cultivate students' enthusiasm for learning. The first class helps strengthen students' overall grasp of this course and enhance students' sense of identity with this course. For teachers, the teaching of the first class also affects whether the teacher can be accepted by the students, the recognition of the teacher by the students, and the degree of importance the students attach to the class. When teachers teach the first class, in order to increase students' interest in learning, teachers can first talk about the history of the development of calculus, especially the stories of the founders of calculus, Newton and Leibniz. The generation of points has a general understanding, Secondly, students should understand the importance of advanced mathematics. It is the theoretical basis for learning other professional courses and directly affects students' subsequent professional courses. Once again, students should understand the difference and connection between advanced mathematics and elementary mathematics, there are differences in the teaching methods of high schools and universities.

High schools focus on lectures. In the classroom, teachers will explain the knowledge thoroughly through repeated and detailed explanations and exercises. On the other hand, 
advanced mathematics emphasizes the understanding of concepts and focuses on the overall structure of knowledge. The logical structure in advanced mathematics is to first give a definition, and then combine the existing mathematical theories to extend many theorems. Perhaps some theorems have been obtained through intuitive perception, such as Fermat's Lemma, and they have also been widely used. However, the study of advanced mathematics is precisely to study the reasons for the establishment of these theorems. In the process of describing problems in mathematical language, students' thinking can be closer to the essence of mathematicsrigorous logic. Therefore, unlike high school, college mathematics requires more initiative, self-consciousness and self-learning ability.

Teachers can ask some enlightening questions related to the content of this chapter when teaching the first class, Or give the knowledge framework of this chapter, tell students what content will be learned in this chapter, and why they should learn it, so that students can learn mathematics in a purposeful and directional manner. For freshmen who are in the transition period, slow down when they first start lectures, Students' understanding is a process of gradual deepening from simple to complex. Only by gradual and orderly progress can students effectively master a system of useful knowledge instead of scattered and messy useless knowledge. In order to develop students' rigorous logical thinking ability, rather than superficial, impetuous, and disorderly cognitive ability. Teachers should grasp the main contradictions in the teaching process, and solve the key points and difficulties.

Therefore, students should feel the unique charm of advanced mathematics in the first class through the guidance of teachers.

\section{CULTIVATE STUDENTS' PATRIOTISM THROUGH THE HISTORY OF MATHEMATICS}

In the teaching of advanced mathematics, the relevant history of mathematics development should be introduced in a timely manner [3]. This will not only enhance students' enthusiasm for learning mathematics, but also enable students to understand the long and tortuous development process of mathematics, so that students can learn more in interesting stories. Deeply understand the knowledge learned, China has a splendid culture since ancient times and brilliant achievements in the field of mathematics. Many achievements in ancient mathematics were once in the leading position in the world. The optimization method initiated by the modern mathematician Professor Hua Luogeng has been widely used in production and scientific experiments, creating great economic value; Mathematician Chen Jingrun has proved the "1+2" Chen's theorem, which shocked the international mathematics community and so on. In the process of mathematics education, the scientific attitude of seeking truth from facts can ignite the light of ideals in students' hearts and establish long-term learning goals; mathematician's spirit of not fearing hardships and powers can infect students and inspire their courage to overcome difficulties and fight tenaciously. mathematician's lively, cheerful and lifeloving mood can influence students, open their minds and relax their minds, thereby forming a healthy and upward outlook on life. The way of thinking and thinking of mathematicians can gradually influence the thinking of students, so that students can imitate and internalize them further, so as to develop good thinking habits.

The growth experience of every mathematician is a touching story, a chapter that purifies people's soul. Their love and perseverance to science, hard work spirit, tenacity and rigorous style, will have a great impact on students. Therefore, teachers should combine textbooks to tell students more touching stories of mathematicians in class or outside class. For example, when talking about irrational numbers, you can intersperse such stories. The discoverer of irrational numbers is Hipassus of the Pythagorean school of ancient Greece. He dared to ask questions of his most authoritative teacher, Pythagoras, and was born. The great discovery in the history of mathematics-irrational numbers, which violates the Pythagorean school's doctrine of "everything is an integer. However, in order to uphold the scientific truth, he did not bow to the forces, and was eventually thrown into the ocean, becoming the first mathematician in the history of mathematics to devote himself to the truth of mathematics. Each story is like a silent spring rain that nourishes the students' hearts, cultivates their sentiments, and plays a subtle role. It helps the students to learn the aggressiveness of scientists and the spirit of perseverance to study and cultivate. Psychologists believe that the will is an important psychological factor for success. A strong-willed person will consciously use practical actions to achieve his predetermined goals, consciously overcome various difficulties, and make his behavior obey the set goals. and weak-willed people will know the difficulties and push. Therefore, having a good character of will is a necessary condition for students to succeed in learning. By training them with a strong will, they can overcome difficulties, laziness and negative emotions, and study hard with perseverance.

Through the history of mathematics, students can understand the past and present of mathematics, which can cultivate students' patriotism and national self-esteem, enable students to establish self-reliance and self-reliance, and stimulate students' sense of responsibility and mission. Arouse the patriotic enthusiasm of the students and cultivate the spirit of hard work for the prosperity of the country and the people.

\section{CULTIVATE STUDENTS' THOUGHTS OF DIALECTICAL VIEW OF MATERIALISM}

In fact, the teaching content of advanced mathematics contains rich materialist dialectics thoughts. For example, when teaching the continuity of functions in the first 
chapter, the allusion of boiling frogs in warm water is introduced, which also allows us to experience the philosophical thinking that quantitative changes cause qualitative changes. When teaching the problem of definite integral, because the idea of solving the problem of definite integral is to divide, approximate substitution, sum, and take the limit, this solution process essentially contains the idea of dividing into zeros and substituting straight for tune.

This also embodies the philosophical thinking of the unity of opposites of contradictions and the qualitative changes caused by quantitative changes.

The idea of mutual transformation of contradictions in materialist dialectics runs through the teaching of higher mathematics [4]. If the teacher conducts an in-depth analysis of the content taught in the course of teaching, he can discover the ideas contained therein. Doing so can improve students' understanding of the concept, thereby improving the teaching effect. For example, after finishing the operation of differentiation and integration, students can find that the integration is the inverse operation of the derivative, which just shows that the derivation and the integration are opposite. And the basic integral formula is essentially derived from the basic derivation formula, which also shows that the derivation operation and the integration operation are unified. When talking about the expansion of power series in Chapter 12, we know that the exponential function has the following expanding

$$
e^{x}=1+x+\frac{x^{2}}{2 !}+\cdots+\frac{x^{n}}{n !}+\cdots(-\infty<x<+\infty)
$$

In particular, setting $\boldsymbol{x}=1$,

Furthermore, we get

$$
\boldsymbol{e}=1+1+\frac{1}{2 !}+\frac{1}{3 !} \cdots+\frac{1}{\boldsymbol{n} !}+\cdots
$$

This shows that an irrational number can be represented by an infinite number of rational numbers, which also reflects the law of contradiction and unity of opposites.

The universality of contradiction and the particularity of contradiction have been demonstrated in many mathematical problems. For example, when talking about the concept of the limit of a sequence of numbers and the limit of a function in Chapter 1. We know that the concept of the limit of a sequence of numbers is

$$
\lim _{n \rightarrow \infty} x_{n}=a \Leftrightarrow \forall \varepsilon>0, \exists N, \ni n>N,\left|x_{n}-a\right|<\varepsilon
$$

The concept of function limit is

$$
\lim _{x \rightarrow \infty} \boldsymbol{f}(\boldsymbol{x})=\boldsymbol{a} \Leftrightarrow \forall \boldsymbol{\varepsilon}>0, \exists \boldsymbol{X}>0, \ni|\boldsymbol{x}|>\boldsymbol{X},|\boldsymbol{f}(\boldsymbol{x})-\boldsymbol{a}|<\boldsymbol{\varepsilon}
$$

Through the comparison of these two concepts, we can see that the concept of function limit is a further promotion of the concept of sequence limit, and the concept of sequence limit is a special case of the concept of function limit. Therefore, in teaching, if the two can be combined for comparison and analysis, the students will definitely have a deeper understanding of him.

Similarly, when talking about the differential mean value theorem, we can see that we first introduced Rolle's theorem. After talking about Rolle's theorem, Rolle's theorem is extended to Lagrange's mean value theorem and Cauchy's mean value theorem. Conversely, Rolle's theorem is a special case of Lagrange's mean value theorem, and Lagrange's mean value theorem is a special case of Cauchy's mean value theorem. Therefore, the content of the differential median theorem just reflects the dialectical unity of the particularity of contradiction and the universality.

\section{CULTIVATE THE HUMANISTIC SPIRIT OF STUDENTS THROUGH THE EXPLANATION OF KNOWLEDGE, SO AS TO TEACH OTHERS}

When teachers are teaching, through the explanation of knowledge points and the combination of curriculum ideology, students are motivated to study hard to achieve the purpose of curriculum ideological and political education [5]. For example, when introducing the concept of the limit of a sequence of numbers, the content can be introduced through the circle-cutting technique of the ancient Chinese mathematician Liu Hui. That is, the area of the regular polygon is inscribed in the circle to approximate the area of the circle. The limit means that it is infinitely close to a fixed value, Teachers can use the definition of limit to encourage students to understand that once a goal is set, they must not forget their original intention and move forward, and eventually they will be infinitely close to the goal.

When learning the partial integral of definite integral, the partial integral formula transforms complex integrals that are not easy to obtain into simple integrals. Through this example, students realize that when encountering problems, they must learn to transform their minds and make them easier. Life is different from exams. Every question in the exam is a must, but in actual life, you can try Try to simplify or bypass the problem and move on.

When learning the extreme value and maximum value of a function, we know that the extreme value is the result in a certain small field, and the maximum value is the result of the entire interval. Therefore, the minimum value is not necessarily the overall minimum value, and the maximum value may not necessarily be the overall maximum value; Through the definition of minimum value, we can see that temporary success does not mean success in life, and temporary failure does not mean that nothing will be accomplished in life.

The "trough" and "peak" in real life are temporary, and by observing the image we find that the minimum value is the end of a decreasing interval and the beginning of an increasing interval;

Similarly, the maximum value is the end of an increasing interval and the beginning of a decreasing interval. Therefore, you should not be pessimistic and desperate about life when you are in a "trough", because "a trough" not only means the end of a low life, but also the beginning of a new life; But at the same time, we should also realize that when we are at the "peak", we should not be arrogant 
and complacent. We must be wary that the "peak" is only temporary, and after the peak, there may be a low ebb in life.

\section{THROUGH THE INTEGRATION OF CURRICULUM IDEOLOGICAL AND POLITICAL THINKING IN THE CLASSROOM TO CULTIVATE STUDENTS' SPIRIT OF ADVOCATING RATIONALITY}

With its strict logical structure, advanced mathematics focuses on reasoning and objective analysis; it plays an indispensable role in guiding and promoting the cultivation of students' rational thinking. Incorporating ideological and political elements into advanced mathematics is an important way to cultivate students' rational thinking. In order to cultivate students' rational thinking in the teaching of advanced mathematics, teachers can dig deeply into the ideological and political elements contained in each mathematical symbol before teaching, and carefully design the teaching of each course. Put curriculum ideology and politics throughout the entire teaching process, and strive to achieve the organic unity of knowledge transfer, ability training and value guidance, For example, when digging about the content of the function in the textbook, you can use the image of the function to let the students see the line changes intuitively, and guide the students to improve their logical thinking by analyzing the rise and fall of the curve, and the characteristics of the cycle. In this way, students are guided to realize that learning also requires a process [6]. Only by developing good learning habits and studying hard, can rational inquiry achieve quantitative change to qualitative change. Mathematics is knowledge that makes people smart. It opens the way for the emancipation of human minds. Its thinking methods can directly help to think about other non-mathematics problems and achieve the purpose of optimized thinking. In the teaching process, students can experience the beauty of the use of mathematical thinking, which will greatly stimulate students' interest.

Furthermore, as advanced mathematics is a difficult subject, students will inevitably feel bored and lose interest. Therefore, in the process of teaching students, teachers can appropriately add some interesting questions and answers or interesting stories. For example, before talking about the most cumbersome part of calculus, you can use the short story of who invented calculus to rekindle the interest of students, thereby improving the quality of teaching.

When students have an interest in learning advanced mathematics, they will naturally understand this subject autonomously. In the process of autonomous understanding, their autonomous thinking ability can be improved, thereby cultivating their rational thinking.

\section{CONCLUSION}

Through the excavation of the content of higher mathematics teaching, the article analyses the method of incorporating ideological and political elements in the classroom of higher mathematics, and selects some typical examples to illustrate the ideological and political elements contained. Thereby increasing students' interest in learning and enhancing the teaching effect of the classroom. Advanced mathematics plays an important role in the formation of students' logical thinking and the cultivation of professional qualities. It is imperative to reform the teaching methods and models of advanced mathematics. Only by taking every class seriously, discovering and correcting problems in time, can achieve the ideal teaching effect.

\section{REFERENCES}

[1] L. Zhang and H. Liu, "The exploration and practice of curriculum ideology and politics in higher mathematics teaching in normal universities," Research and Practice of Innovation and Entrepreneurship Theory, vol. 3, pp. 17-19, February 2021.

[2] R. Jia and J. Wang, “On the ideological and political teaching in advanced mathematics", School of Science, Liaoning University of Science and Technology, vol. 18(2), pp. 158-159, January 2020. (references) DOI:10.16661/j.cnki.1672-3791.2020.02.158

[3] X. Wang, L. Liu and X. Meng, "Research on the Path to the Integration of Ideological and Political Education into Advanced Mathematics Course", Tianjin University of Science and Technology, vol. 2, pp. 7175, March 2020.

[4] Y. Zhang, H. Ding, "Exploration and Practice of Philosophical Elements in Higher Mathematics Teaching under the Curriculum Ideological and Political Background", Tianjin University of Science and Technology, vol. 42(4), pp. 120-125, April 2021. (references) DOI: 10.13877/j.cnki.cn221284.2021.04.018

[5] D. Liu, C. Cao, J. Liu and X. Wang "Ideological and Political Exploration of Advanced Mathematics Course and Analysis of Classic Cases", Journal of Beijing Union University, vol. 35(3), pp. 34-38, July 2021. DOI:10. 16255 /j.cnki.ldxbz.2021. 03. 007

[6] Y. Zhu and Q. Wu "How to integrate ideological and political education in advanced mathematics class", Studies in College Mathematics, vol. 24(4), pp. 106-108, July 2021. DOI:10. 3969 /j.issn.1008-1399.2021.04.034. 